\title{
As Comunhões Anglicana e Católica Romana face aos Desafios Éticos da Sexualidade Moderna
}

\author{
Dr. Frei Carlos Josaphat
}

\begin{abstract}
RESUMO
ABSTRACT

Neste último século, vão emergindo ou avançando vagas crescentes de emancipações e inovações, ao mesmo tempo culturais, éticas, jurídicas, políticas e religiosas, que são importantes para civilização moderna ou pós-moderna.

Palavras-Chave: inovações, éticas, políticas

In this last century, emergent inovations culturais ethics, juridics, politics end religious, are importants to modern end pos-modern civilization.

Key-words: inovations, ethics, politics

\section{INTRODUÇÃO}

De que forma e com que êxito, os fiéis de Cristo, as diferentes reagido ou respondido aos desafios da ética sexual na modernidade? E comunhões cristãs, especialmente a anglicana e a católica romana têm hoje, na fidelidade à graça do ecumenismo, à luz e sob o suave impulso do Espírito Santo que trabalha nos corações, nas comunidades e também no seio da sociedade, como podemos ter a felicidade de enfrentar, juntos, esses graves problemas humanos, na docilidade ao Evangelho e no empenho de ouvir e servir a humanidade?
\end{abstract}

Eis nossa questão em toda a sua amplidão, agudeza e complexidade. 


\section{AS QUESTÕES CRUCIAIS DA SEXUALIDADE PARA A SOCIEDADE MODERNA E O CRISTIANISMO HOJE}

Neste último século, vão emergindo ou avançando vagas crescentes de emancipações e inovações, ao mesmo tempo culturais, éticas, jurídicas, políticas e religiosas, que são como a ponta de lança da civilização moderna ou pós-moderna.

Essa torrente inovadora tem sua fonte no anseio generalizado ou na ampla aspiração pela liberdade de ser feliz, dispondo e usando de tudo para viver intensamente com prazer, na concentração de bens, no acúmulo de recursos e de conforto, dando destaque à valorização erótica e estética do corpo. De início, essa maré montante encontrava certa barreira em certa faixa da sociedade que apelava para a moral, vendo nela uma força de preservação e coesão da própria sociedade.

A religião era chamada a ser o amparo das classes ou elites dominadoras, como fora outrora a capelã das dinastias e das nobrezas.

Mas essa oposição da sociedade a nova era ética e religiosa, foi cedendo mais e mais, buscando formas de acomodação, de integração, aderindo ao que se chamam as formas alternativas de sexualidade, de matrimônio e de família, homologadas pelo direito, legitimadas por modelos de convivência na diferença. Proclamam-se bem-vindas as mudanças, contanto que a pluralidade ou a diversidade não estorvem e antes favoreçam o jogo da sociedade liberal, o comércio, o consumo, a boa extensão e a fluidez rápida e segura da circulação econômica.

Se a sociedade tende a se acomodar, a integrar o pluralismo ético às religiões, especialmente às Igrejas cristãs, experimentam dificuldades específicas, encarando as novidades à luz da mensagem bíblica e tradicional. Apelam portanto, para critérios absolutos, encerrando ao menos um núcleo imutável, com o qual se possa apreciar as atitudes, as tendências e movimentos históricos, que comportam e até mesmo impulsionam elementos de variação, de mudança e de relatividade.

Um primeiro elemento relevante para nosso propósito é que sob o ângulo psicológico e sociológico, em todo grupo, em toda sociedade, em toda entidade social, há sempre duas famílias de espíritos, uns que tendem espontaneamente para a renovação, "é novo portanto, é bom"e os conserva- 
dores para quem a tradição há de ser sempre respeitada, "o novo é sempre pelo menos suspeito".

Esses dados são condições preliminares para abordarmos como convém o problema ecumênico com as posições das Igrejas Anglicana e Católica no confronto com os problemas e desafios da ética sexual. É a interrogação lançada hoje às Igrejas pela prática generalizada dos homens, das mulheres e nas tendências e movimentos reivindicatórios, cujas bandeiras são os valores da liberdade, da tolerância, e mesmo da felicidade individual dentro da convivência social.

Tentando fixar umas datas de referência, diríamos que após a cessação do primeiro conflito mundial em 1919-20, e desde o segundo 1946, e anos seguintes, o mundo ocidental inaugura ou acelera essa corrida pela emancipação, por uma ruptura com as tradições e autoridades no plano social, cultural, sobretudo ético e religioso.

Essa tendência libertária vai se acentuando e intensificando, exaltando e cultivando o sexo como a energia valorizadora do indivíduo, como fonte de prazer, que juntamente com o conforto, a forma e o poder, garantem a felicidade e o gosto de viver. Na verdade, esse processo social marcado pelo anseio ou aspiração por uma vida mais livre, tranqüila, assinalada por uma busca geral de mais liberdade, de distanciamento de tudo o que evoca o sufoco totalitário, tudo isso é visto em conexão e sobretudo em contraste com certos limites e imposições das tradições morais e religiosas. Estas são desqualificadas com tabus judeu-cristãos, o que lembra certo neo-paganismo que remonta ao humanismo renascentista.

A moral sexual que assegurava até então certa correção nas sociedades e nas famílias tradicionais, sobretudo a moral cristã é batida em brecha, relegada entre as velharias que a ciência e a técnica teriam deixado para trás.

Duas formas de comunhões cristãs, a anglicana e a católica romana buscaram responder ao desafio, assumindo modalidades semelhantes enquanto ambas apelam para o dado positivo de uma tradição, mas adotando modelos diferentes, dada a diversidade que mostram as duas comunhões em sua compreensão respectiva dessa tradição e de sua relação com a evolução cultural da humanidade e com os diferentes modelos éticos que nela vão surgindo. 


\section{ENCONTROS E DESENCONTROS DAS IGREJAS DIANTE DOS DESAFIOS ÉTICOS.}

É oportuno e enriquecedor esboçar ao menos em suas grandes linhas o duplo paradigma de ética sexual que vem apresentando ao mundo moderno a Igreja Anglicana e a Católica Romana. Convém evocar as posições doutrinais significativas, as questões cruciais, cada vez mais amplas e mais agudas, as prioridades e os critérios privilegiados nos encontros e desencontros dessas duas comunhões. O momento é oportuno para se esboçar algumas sugestões no sentido de favorecer os encontros entre elas e com os valores e aspirações da modernidade.

A emancipação sexual generalizada está no centro da revolução libertária globalizada. Tal é o fio condutor para a compreensão da modernidade, e mais ainda da pós-modernidade, cujo despertar se pode situar nos anos 20 do século passado. A modernidade se ligava à racionalidade, primeiro filosófica, depois científica, num ímpeto de rejeição do tradicionalismo e do autoritarismo, sobretudo religioso. Ao passo que a pós-modernidade radicaliza a tendência desfazendo-se de muros e normas mesmo as simplesmente racionais e fazendo confiança apenas à própria experiência individual.

Desde o começo de seu pontificado em 1921, Pio Xl,embora tenha assumido o mesmo nome de Pio $\mathrm{X}$ e o seu mesmo empenho de instaurar 0 Reino de Cristo, passou a pautar sua atividade pastoral segundo o modelo de Leão XIII. Ele retoma então, e atualiza os temas nos quais este Pontífice tinha tentado esclarecer as grandes questões que Pio IX tinha estigmatizado com anátemas, recusando homologar as liberdades e os direitos humanos proclamados a partir da Revolução Francesa. Ao passo que Leão XIII e Pio $\mathrm{XI}$ se mostraram assim desejosos de dialogar, mas de forma bastante crítica, com as tendências liberais do mundo moderno.

Entre outras comemorações, Pio XI vê a importância em marcar os quarenta anos da encíclica Arcanum, de 1880, sobre o matrimônio cristão, como fará em 1931, com a encíclica Quadragésimo Anno, que marca o quadragésimo aniversário da Rerum novarum (15/05/1891).

Na encíclica Arcanum, Leão XIII tentava exorcizar os perigos de secularização representados pelo casamento civil e pelas ameaças do divórcio. No entanto, não é ainda abordada a série de problemas cruciais que se anunciavam e eram inaugurados pela entrada dos preservativos masculinos. 
Já desde a segunda metade do século XIX, várias intervenções da Cúria Romana estigmatizavam sob o nome onanismo as práticas anticoncepcionais.

Note-se, no entanto, que se percebe certa hesitação inicial em aprovar o recurso ao exercício da sexualidade em períodos naturalmente infecundos. O que depois será dado como ponto seguro, senão o essencial da doutrina católica atual?

Podemos agora apreciar o teor e o espírito da encíclica Casti connubii de 1930, com a qual Pio XI pretendia comemorar, aprofundar e adaptar os ensinamentos dados quarenta anos atrás por Leão XIII na encíclica Arcanum, Seguindo esse propósito de imitar e prolongar Leão XIII, confrontando a mensagem do Evangelho com as aspirações, interrogações ou negações do mundo moderno, Pio XI fazia trabalhar uma equipe de teólogos sobre o tema do matrimônio cristão para Ihe consagrar uma encíclica que parecia cada vez mais urgente. ${ }^{1}$ Pois, os problemas se mostravam muitíssimo extensos e agudos. As questões clássicas do divórcio e do aborto se agravaram assumindo novo feitio com a aprovação generalizada do maltusianismo e da contracepção.Simplificando uma problemática complexa, a questão mais premente se generalizava: como se ter o máximo de prazer e de sexo, e o mínimo de natalidade e mesmo de gravidez.

Chegamos ao momento crucial dos encontros e desencontros das posições romanas e anglicanas. Em 1930, a Conferência de Lambeth já enfrentava o problema, quando o Papa esperava o encerramento dela, para pôr termo à sua encíclica, que finalmente será datada, antedatada, para sair ainda como produzida naquele ano (31/12/1930).

A Conferência se propõe a elaborar um paradigma de inspiração cristã que busque atender às aspirações e tendências da modernidade. Mas só o consegue fazer por uma maioria expressiva, sem chegar no entanto à unanimidade. Seu intento teológico e pastoral de abrir caminhos esbarrará no risco de ser suplantada pelos partidários da pós-modernidade e pelos mais apegados à tradição.

\footnotetext{
Um desses teólogos é Arthur Vermeersch (1838-1936), jesuíta, professor de teologia moral na Gregoriana, em Roma de 1918 a 1934), formador de gerações de teólogos moralistas. Ele acompanhou de perto o desenrolar da Conferência de Lambeth, deixando-nos um excelente artigo documentário e crítico, tanto mais importante que Vermeeersch é sem dúvida um dos assessores do Papa na elaboração da encíclica Casti Connubii.Utilizamos seu artigo: La Conférence de Lambeth et la morale du Mariage, em Nouvelle Revue Théolgique, dezembro 1930, 1-29, utilizando e traduzindo sua versão francesa dos textos da Conferência.
} 
A crise cresce no seio do anglicanismo à medida que os desafios se ampliam e radicalizam. A Igreja católica opta por afirmar simplesmente a tradição, tida como expressão da lei divina, que se traduz nas exigências da lei natural, convergindo na exclusão absoluta de todo meio anticoncepcional artificial, opondo-se assim radicalmente à modernidade e depois à pós-modernidade.

Condensemos uma exposição que nos sirva de ponto de partida e de referência.

\section{PONTOS CENTRAIS DE ACORDOS E DIVERGÊNCIAS.}

A Conferência de Lambeth de 1930 ousa propor uma posição então inovadora, mas mostra uma atitude bastante compreensiva e que procura ser atenta a todos os dados do problema.

Convém salientar dois pontos que de maneira consciente ou inconsciente continuam sempre presentes, grandemente problemáticos senão inquietantes no ensinamento eclesiástico e sobretudo da moral sexual.

O primeiro é a própria visão do sentido humano e cristão da sexualidade. Há uma persistência de certo pessimismo que atravessou a história da cristandade, prolongando a visão estoicista, de uma razão ética que domina e exclui a paixão, fortemente homologada no cristianismo por Santo Agostinho e mais ainda pelo augustinismo que exagera as posições do grande Doutor. Ora, a Conferência proclama na sua resolução 13:

"A Conferência insiste sobre esta verdade que o instinto sexual é coisa santa, implantada por Deus na natureza humana. Ela reconhece que as relações conjugais que consumam o matrimônio,têm nesse sacramento um valor em si, pelo qual o amor conjugal é sublimado e seu caráter se encontra assim reforçado. Além disso, reconhecendo que o fim para o qual existe o matrimônio é a procriação de filhos. A Conferência crê que esse fim, assim como a suprema importância na vida conjugal de um domínio de si refletido e consciente, devem servir de princípios diretivos para as relações conjugais".

Por essa posição que tão sabiamente se distancia da famigerada doutrina augustinista da concupiscência em seu sentido pejorativo de apetite em si desordenado de prazer sexual, a Conferência busca uma atitude inspirada pelo Evangelho e atenta à realidade dentro do contexto cultural moderno, visando enfrentar o delicado problema da regulação da natalidade. 
Antes de considerarmos a resolução da Conferência sobre a limitação da natalidade, é instrutivo ler a apresentação da posição católica feita pelo Comitê que não tem a autoridade oficial da Conferência, mas que é por ela aceita como referência para sua resolução.

O texto do Comitê assim se exprime:

No seio da Igreja Católica, uma tradição verdadeiramente forte sustenta que o uso dos métodos preventivos não pode em caso algum se legitimar para um cristão. Reconhecendo o peso dessa tradição, nós não poderíamos aceitá-la como necessariamente definitiva. Ela não está fundada em qualquer orientação dada no Novo Testamento. Ela não está apoiada pela autoridade de um Concílio Ecumênico na Igreja. Além disso, fato significativo. Esta comunidade que em princípio lança sobre os métodos preventivos a condenação mais severa, reconhece todavia que há ocasiões em que a observância rígida desse princípio é impossível. (Artigo citado p.18).

Eis agora o texto da famosa resolução 15 da Conferência, legitimando a prática bem ordenada da contracepção, resolução exaltada ou malsinada como inovadora:

Quando se constata claramente a obrigação moral de limitar ou evitar a paternidade, o método a seguir deve ser decidido segundo os princípios cristãos. O método natural que primeiro se apresenta é a abstinência completa das relações em uma vida disciplinada e dona de si, levada graças à virtude do Espírito Santo. Contudo, no caso em que se constata claramente que essa obrigação moral de limitar ou evitar a paternidade, e que uma razão moralmente sadia se opõe a uma completa continência, a Conferência admite que outros métodos possam ser empregados, contanto que isso se faça à luz dos mesmos princípios cristãos. A Conferência lembra a sua enérgica condenação de todo método anticoncepcional adotado por motivos de egoísmo, de volúpia ou de pura conveniência.

Essa posição poderia ser entendida como o convite a um diálogo dentro das comunidades anglicanas e destas com a Igreja católica, cuja posição o Comitê declarava digna de ponderação, embora não "definitiva". 
A resolução aprovada por mais de dois terços dos prelados participantes da Conferência, ${ }^{2}$ provocou discussões tendendo ou chegando mesmo a ser aceita em grande escala entre cristãos anglicanos. Ao contrário encontrou a reação de total oposição do Magistério oficial da Igreja Católica, bem como dos teólogos que o assessoravam e, em seguida, de quantos se viam na obrigação de seguir esse ensinamento oficial da autoridade eclesiástica.

Sempre na perspectiva de uma busca de oportunidades para um diálogo cada vez mais necessário e tentamos pôr em relevo o teor e significado das posições da igreja católica.

\section{SENTIDO HISTÓRICO E DOUTRINAL DA RADICALIDADE CATÓLICA.}

É da maior importância compreender o sentido da radicalidade da doutrina católica desde a encíclica Casti Connubii de Pio XI, 31/12/1930.

O Papa e sobretudo seus teólogos acompanhavam com o maior dos interesses as atividades da Conferência de Lambeth, que tinham inaugurado oficialmente em 9 de agosto de 1930.

Fazendo uma alusão clara à Conferência mas sem a mencionar, Pio XI faz uma condenação solene da contracepção. Depois de citar Santo Agostinho, o Papa proclama: "Por conseguinte, havendo alguns que se afastando manifestamente da doutrina cristã, ensinada desde o princípio e nunca modificada, pretenderam publicamente propor, há pouco, doutrina diversa acerca deste modo de proceder a Igreja Católica, a quem o próprio Deus confiou a missão de ensinar e defender a integridade e a honestidade dos costumes, colocada no meio desta ruína moral para preservar a tanta torpeza, a castidade da união conjugal que proclama altamente e de novo promulga pela nossa palavra: qualquer uso do matrimônio em que, pela malícia humana, o ato seja destituído de sua natural força procriadora, infringe a lei de Deus e da natureza. $E$ aqueles que ousarem cometer tais ações, se tornam réus de culpa grave". (Enc. Casti connubii, No. 21).

A interdição da contracepção é proclamada como doutrina primitiva e jamais alterada como lei de Deus (contida na condenação de Onã, em Gn $38,8-10$ ) e como lei da natureza (pois o ato sexual é dotado de uma força

2 Eles eram 260, tendo 193 votado a favor e 67 contra. 
ou orientação natural procriadora). Por outro lado, o Papa insiste na missão divina da Igreja católica de ensinar e defender a integridade e honestidade dos costumes, em clara alusão, nada ecumênica, à deficiência de outra comunidade e a anglicana.

Na nossa perspectiva do diálogo ecumênico, vê-se a importância desses dados. Com efeito, entre os fiéis e teólogos católicos havia um interesse positivo pelo que sucedia em Lambeth e no anglicanismo em geral, pois em seu conjunto, a Igreja católica passava por uma evolução favorecida pela valorização do laicato com o progresso da Ação Católica e da espiritualidade dos casais e da família.Todos esses setores do Catolicismo esbarravam nos difíceis problemas da ética sexual.

Um pouco mais tarde, dentro desse contexto doutrinal e espiritual, um teólogo católico publica uma obra que terá a maior repercussão, pois tentava homologar teologicamente esse progresso espiritual na Igreja, enfrentando o que parece um impasse ocasionado pela interdição da contracepção formulada pela encíclica Casti connubii. Em 1935, Herbert Doms lança em alemão o livro Sentido e fim do Matrimônio, amplamente acolhido como a desejada e harmoniosa conjunção da tradição e dos desafios atuais. Ele expõe o fim do matrimônio conforme a tradição. Este fim é a procriação e a educação dos filhos. Mas essa finalidade é envolvida pelo sentido do matrimonio, sentido que vem a ser a união do casal no amor, no dom de si um ao outro. É este sentido que faz da união conjugal uma aliança plenamente humana, dando valor à união sexual e dela fazendo uma linguagem concreta do amor e da felicidade de amar.

Doms utiliza uma reflexão de Pio XI (Casti connubii, No. 9) que define o matrimônio como união das pessoas em vista do seu aperfeiçoamento, portanto em acepção mais ampla e abrangente do que a instituição para a procriação.No entanto, quando o livro Herbert Doms ia-se traduzindo e difundindo, foi condenado por Pio XII em 1944.

Alargando a perspectiva, podemos dizer que a doutrina e a moral do matrimônio, da sexualidade e da transmissão da vida em geral, amadurecem na experiência dos fiéis, mas não encontram uma expressão satisfatória nos ensinamentos oficiais do Magistério da Igreja Católica até os fins do pontificado de Pio XII (1958), malgrado os progressos realizados em vários pontos importantes como a valorização do prazer, do corpo, a exaltação do amor e da missão da mulher no lar, e muito especialmente, a difusão de uma espiritualidade conjugal e familiar. 
Em confronto com certa maleabilidade da Igreja anglicana em seu empenho de se manter fiel ao Evangelho no contexto da atualidade, é da maior importância ecumênica procurar entender o sentido da intransigência radical do Magistério da Igreja católica no que toca a contracepção e assuntos afins.

A referência ao texto bíblico sobre o onanismo (Gn 38,8-10) perdeu sua pertinência, a luz dos progressos da hermenêutica atual, não sendo mais utilizado oficialmente desde Paulo VI. Uma doutrina enraizada na tradição primitiva e permanente da Igreja, cujo conteúdo é de lei natural, que a Igreja só pode e deve respeitar, transmitir e jamais modificar, eis o que constitui o dado essencial, intocável da contracepção para o Magistério da Igreja Católica.O ser humano, em sua unidade pessoal e em sua constituição de corpo e alma, em sua dimensão orgânica, fisiológica, biologia, psicológica e espiritual é, a luz da razão, uma natureza singular em sua dignidade, sendo no plano da fé, uma criatura privilegiada e amada de Deus e por Ele tornada objeto de todo amor, cuidado e respeito.

Tal é a questão crucial e essencial stantis vel cadentis Ecclesiae, do ser ou não ser, para a Igreja Católica; o que perdura até o Concílio Vaticano II. E então?

\section{VATICANO II E A ETAPA PÓS-CONCILIAR EM REFERÊNCIA AO DIÁLOGO COM A IGREJA ANGLICANA}

São bem conhecidos os progressos realizados com Vaticano II, em sintonia com a marcha das diferentes confissões cristãs, pois o diálogo ecumênico foi uma das fontes de enriquecimento da Igreja católica de que o Concílio foi a expressão de vulto universal. Vou me restringir ao ponto preciso da sexualidade e mais precisamente da contracepção, pois são bem significativos os encontros e os desencontros pós-conciliares.

Destaquemos os seguintes dados e momentos mais marcantes.

Quando se abriu o Concílio em outubro de 1962, os Padres conciliares tinham em mãos um anteprojeto elaborado pela comissão pré-conciliar sob a égide da Cúria Romana, tendo como título "Constituição dogmática sobre a Castidade, o matrimônio, a família e a virgindade". Era o resumo bem reforçado do que se considerava a tradição, insistindo sobre os "bens próprios", "os fins naturais do matrimônio" e dando maior relevo à condenação 
dos erros modernos. Dentre esses, se destacam especialmente os métodos contraceptivos, rejeitados em nome da tradição, mas só sendo citada a encíclica Casti connubii de Pio XI.

Deixando de lato tal anteprojeto, muito laboriosamente o Concílio chegou a propor um belíssimo capítulo com o título "Promoção da Dignidade do Matrimônio e da Família". Interpretava bem a tradição e ia ao encontro das melhores aspirações atuais mostrando no matrimônio o sacramento do amor, visando primeiro a felicidade e a santificação dos cônjuges para que estejam a altura da missão de transmitir a vida e educar a prole na responsabilidade e no amor.

O Concílio preparou uma posição satisfatória para o problema da regulação da natalidade, indicando os critérios éticos para tal discernimento. Ele partia simplesmente do conceito de natureza, propondo que se assuma de maneira integral a noção de natureza pessoal e da conformidade do exercício da sexualidade em conformidade com essa natureza pessoal, e não com a natureza em sua dimensão parcial biológica. Retirando ao Concílio a missão de determinar esses critérios, no que toca a escolha dos medos de regulação da natalidade, reservando a si este julgamento, Paulo VI ampliava a Comissão que devia preparar o seu pronunciamento, elevando há mais de setenta, o número de especialistas que a compunham. ${ }^{3}$

Na linha de nosso propósito e para nosso diálogo proponho-lhes apenas dois dados importantes-

- em sua perspectiva própria e original, Vaticano II se aproximava da posição já esboçada pela Conferência de Lambeth de 1930;

- mas ainda a maioria da Comissão nomeada pelo Papa para preparar seu pronunciamento, retoma em substância a posição, a perspectiva, as motivações e argumentos da mesma Conferência em seu documento sobre o tema acima mencionado.

Bem contrária será a posição adotada pela minoria da Comissão sob a orientação do Cardeal Ottaviani, minoria que por influência do mesmo Cardeal,

\footnotetext{
Bem sabemos, a promulgação de Humanae vitae foi apressada pela divulgação indiscreta dos textos da Comissão pontifícia preparatória e finalmente pela sua publicação integral por Jean-Marie PAUPERT nas Éditions du Seuil, em 1967,logo traduzidos em português e editados pelas Vozes de Petrópolis...
} 
será seguida por Paulo VI na encíclica, problemática ou profética, Humanae vitae (27/07/1968). Em seu famoso número 14, ela retoma, atualiza e prolonga a mesma posição da encíclica Casti Connubii de dezembro de 1930.

Não deixa de ser um tanto intrigante, mas sobretudo imensamente significativo esse jogo de encontros e desencontros da parte de cristãos de boa vontade e que têm tudo a ganhar dialogando com muita inteligência em busca da verdade e sob o impulso do amor.

\section{CONCLUSÃO}

\section{Urgência e qualidades do diálogo, sobretudo em torno da ética sexual}

Há sem dúvida uma urgência urgentíssima que os cristãos, os fiéis, as comunidades e suas autoridades se empenhem em um diálogo em busca do entendimento em torno de um núcleo de certezas sobre a ética sexual e sobre as respostas a dar aos grandes e angustiosos problemas que a humanidade enfrenta nesse domínio crucial e essencial para as pessoas e para a sociedade.

Bem se vê, se o diálogo é urgente, ele é ainda mais exigente sobre o conjunto de qualidades que hão de ter as pessoas e as comunidades, porque o tema é da maior importância e suma dificuldade. É indispensável analisar o fenômeno da divergência, o que há de normal na diversidade de tendências, bem o que se torna problemático e com o tempo deve ser superado em espírito de compreensão e confiança.

\section{Decálogo ecumênico}

A título de exemplo e de simples amostragem vou tentar propor um feixe de qualidades, uma espécie de decálogo ecumênico em torno da sexualidade, em busca de uma ética e de uma espiritualidade sexuais.

1. Não ter medo de enfrentar a realidade. A humanidade, digamos $O$ mundo ocidental, tecnológico e globalizado, em matéria de moral sexual não dispõe de doutrina dotada de credibilidade e parece não ter o controle mínimo da sexualidade para chegar ao mínimo de equilíbrio no amor, na fidelidade, na constituição do casal, da família e da educação dos filhos. 
2. Trabalhar para nos entender e propor um núcleo de moral sexual para a humanidade hoje, é um imperativo prioritário para o cristianismo e mesmo para todas as religiões.

3. O diálogo há de ser universal, não de certa elite intelectual ou espiritual. É imprescindível distinguir bem as funções dos pastores ou das autoridades religiosas, dos teólogos e dos fiéis, das pessoas, famílias comunidades, e bem articular as contribuições de todas elas. Que as comunidades tenham consciência dessa diversidade e dessa complementaridade indispensável das funções e dos carismas.

4. O diálogo entre as confissões cristãs só será autêntico e eficaz se for precedido, preparado e acompanhado pelo diálogo dentro de cada confissão e não para chegar à solução dos problemas, o que de imediato seria inviável, mas para preparar o diálogo com as confissões, - diálogo que é necessário para colocar bem as questões e avançar na busca de soluções.

5. No diálogo interno de cada comunidade e no diálogo intercomunitário, cumpre saber discernir e aproveitar as contribuições próprias e complementares das diferentes funções: dos pastores, dos teólogos, dos fiéis na diversidade de suas profissões e presenças no mundo. Pois bem se vê, as experiências dos fiéis significam uma competência que outras funções, pastores e teólogos em geral não têm. Assim, como os fiéis hão de reconhecer a autoridade dos pastores e a especialidade dos teólogos? A competência da autoridade, da experiência e do saber não se opõem, mas se hão de completar mediante um difícil labor de encontro e de diálogo.

6. Destaca-se aqui uma grande lição da Constituição dogmática de Vaticano II Dei Verbum (18/11/1965), em geral disseminada nos documentos e encontros ecumênicos, sobretudo mais recentes a saber: o Evangelho, a Palavra viva e salvadora de Deus, se faz presente mediante a conjunção de um feixe de dons divinos complementares e que não têm plena eficácia quando se exercem separadamente.

- Na transmissão viva da Revelação, há de haver primeiro, a convergência dos protagonistas: os fiéis que acolhem e meditam a Palavra, os mestres que a estudam e os Pastores que têm o ofício de proclamá-la.

- Em segundo lugar, sob o aspecto das fontes dessa tradição ou transmissão da mensagem, se terá sempre que contar com a conjunção do testemunho primordial da Escritura, da tradição de ontem e de hoje e do magistério vivo da Igreja (Cf. Constituição citada, todo o capítulo II). 
Uma das maiores urgências na Igreja católica romana é que seja hoje estritamente fiel ao que teve a felicidade e a graça de receber nesse carisma comunitário que foi o Concílio Vaticano II.

7. A missão dos Pastores não é primordialmente vigiar os fiéis e os teólogos, mas estimulá-los a viver a fé e a fazer valer os carismas próprios.

8. Igualmente a função dos teólogos e dos fiéis não é a de serem simplesmente receptores ou repetidores passivos

9. Ainda uma orientação de Vaticano II que não parece estar em sintonia com as diferentes confissões cristãs, muito especialmente com a Igreja anglicana a saber: a necessária atenção à "hierarquia das verdades" dentro da atitude de constante e total docilidade a todo o Símbolo da fé (Vaticano II, Decreto sobre o ecumenismo, No. 11).

Em todas as questões cruciais e melindrosas enfrentadas pelas Igrejas, no nosso caso Anglicana e Católica, estão em jogo elementos, assumidos em bloco mas que considerados separadamente têm uma consistência muito variável. Uma coisa vem a ser a mensagem evangélica do respeito, da sexualidade, do corpo "templo do Espírito Santo", e bem outra, o registro cultural que exprime esse dado da palavra de Deus em termos de "natureza, de natureza humana, de natureza da sexualidade, de tal ato sexual".

Portanto, hoje seria mais do que conveniente, absolutamente indispensável determinar o sentido de termos dotados, de uma verdadeira polissemia, de uma pluralidade de sentidos conexos, mas não necessariamente idênticos, tais como: natureza, natureza humana, leis naturais; será também indispensável examinar as mediações racionais, os valores éticos que estão em jogo e a serviço da compreensão da mensagem da santidade, da espiritualidade e da ética evangélicas.

De modo geral, seria oportuno destacar vários campos de pesquisa relevantes e mesmo urgentes para um trabalho ecumênico. Esses campos de estudo e reflexão poderiam ser apresentados e ilustrados pelos conhecidos pares de conceitos afins: valores e modelos, valores evangélicos, éticos, pessoais, familiares, sociais, valores de si absolutos e imutáveis, modelos históricos, formas culturais, de si mais ou menos permanentes ou mesmo contingentes e passageiras; são modalidades concretas que os valores revestem em um momento da sociedade, em uma fase da vida da Igreja ou em uma etapa da evolução da instituição familiar. 
O que dizemos dos valores absolutos e dos modelos históricos se estende a outros pares de noções que fazem parte de nossa linguagem teológica e pastoral: natureza e cultura, tradição e progresso das doutrinas e das práticas da Igreja, autoridade eclesiástica e participação dos fiéis.

O ecumenismo é o amor, é a caridade impelindo e iluminando as inteligências para enfrentar e discernir os problemas mal definidos que se vêm arrastando através da história, semeando ambigüidades, desentendimentos e divisões.

10. Em síntese e conclusão. É preciso crer no diálogo enquanto comunhão dentro de cada comunidade eclesial e entre as diferentes comunidades. É urgente universalizar e aprofundar o diálogo, sabendo que só se aprende a dialogar dialogando, tirando proveito dos êxitos e dos fracassos, na certeza de que o dom do Espírito não suprime ou resolve os problemas, mas nos dá a coragem, a arte e a paciência de enfrentá-los.

Se a Igreja apostólica, a Igreja mãe de Jerusalém como se lê nos Atos, 15 , após uma assembléia sobre o essencial, sobre a identidade do ser cristão, declarava: "Aprouve ao Espírito Santo e a nós" tomar essa decisão, essa audaciosa conjunção "o Espírito Santo e nós" não decorre da experiência de um sopro do Espírito nos ouvidos de Pedro, dos Apóstolos ou de um ou outro membro da Igreja, iluminado por um carisma individual. Essa convicção de fé brota sim da certeza de que a comunidade estava na plena docilidade ao Espírito nela presente. Em que se fundava essa certeza? No fato de se reunir, de se escutar, de dialogar, de receber assim a Luz do Espírito que fala, age e habita em todos e em cada um dos que formam a comunidade dos fiéis de Cristo.

Onde há escuta recíproca, onde há diálogo, onde há comunhão, aí está o Espírito da Verdade, do Amor e da Paz.

Dr. Frei Carlos Josaphat OP

Teólogo dominicano

\section{BIBLIOGRAFIA}

Vaticano II, Decreto sobre o ecumenismo, n. 11.

Dei Verbum (18/11/1965).

Humanae vitae (27/07/1968).

Casti Connubii (dezembro de 1930). 